\title{
Health promotion and drug abuse prevention
}

\author{
Christiane Hillger • Martin Huber • Wilhelm Kirch
}

Published online: 27 May 2011

(C) Springer-Verlag 2011

\begin{abstract}
Alcohol and drug abuse are important health issues in European countries, affecting both the individual person and the whole society. According to the 2008 Annual Report of the European Monitoring Centre for Drugs and Drug Addiction, the estimated lifetime prevalence of, for example, cocaine use in people aged 15-64 years is at least 12 million, which means $3.6 \%$ of all European adults. One to six out of 1,000 adults are problem opioid users (e.g. taking heroin); of these, more than 600,000 received substitution treatment in the year 2006 (EMCDDA 2008). Also drug abuse, addiction and drug-related crime are a major and still rising phenomena in Croatia, which might be due to the fact that the country is situated on the "Balkan Route" of heroin supply for Western Europe (EMCDDA 2008).
\end{abstract}

However, not only illicit drugs are a problem, but also overconsumption of alcohol plays an essential role in this context. Regarding the total recorded alcohol per capita consumption (of people aged 15 years and older, in litres of pure alcohol), Germany and Croatia have leading positions among all countries worldwide (WHO 2004).

The aforementioned issues underline the importance of adequate measures to prevent drug addiction, and to strengthen health promotion activities in general. To reach this goal, it is essential to address health professionals (e.g. physicians, psychologists, etc.) working in this field. Postgraduate study courses on a university level can provide the knowledge enabling them to work with addicted individuals and to promote prevention initiatives.

\footnotetext{
C. Hillger $(\square) \cdot$ M. Huber $\cdot$ W. Kirch

Research Association Public Health Saxony and Saxony-Anhalt, Faculty of Medicine, Technische Universität Dresden,

Fiedlerstraße 33,

01307 Dresden, Germany

e-mail: christiane.hillger@tu-dresden.de
}

At the University of Rijeka in Croatia, which is rapidly progressing towards joining the European Union and has recently become a Candidate Country, a European consortium including experts from Poland, Germany and local institutions implemented an interdisciplinary postgraduate course dealing with health promotion and drug abuse prevention. This was done within a Tempus project funded by the European Commission: grant agreement number CD_JEP-41030-2006 (HR) - a programme framework supporting countries of the Western Balkans and other regions in modernising their higher education mainly through university cooperation (http://eacea. ec.europa.eu/tempus/index_en.php). The project primarily was aimed at building and strengthening the institutional capacity in Croatia to establish the aforementioned course. The main emphasis of the study programme lay on transfer of knowledge and development of practical skills, addressing health and education professionals as well as staff of public administration and non-governmental organisations working in the field of drug prevention and health promotion. The first curriculum containing two semesters was successfully completed in 2009.

In their article Risk analysis in the period of growing-up of children and youth: starting point for effective prevention, Bašić, Mihić and Novak focus on the elaboration on determinants of society "at risk". They concentrate on the very important and relevant factor of the younger population, their problems and the handling of special behavioural risk factors. On the basis of numerous longitudinal studies, the authors detected the most relevant risk factors for children and adolescent and, thus, refer to a better and comprehensive understanding with regard to preventive strategies on this issue.

Despite increased levels of anxiety, depression and reduced self-esteem, alcohol abuse is one of numerous results for unemployment of young adults. Reissner et al. 
describe in their article Psychiatric disorders and health service utilisation in unemployed youth the situation of unemployed youth and associated psychiatric disorders and related constructs. The underlying study is the first one that assessed personality and non-personality aspects. Results shall be used for supporting employment programmes for psychiatric disorders.

The process of establishing behaviour and lifestyle choices affect future health. Healthy diet, physical activity, smoking and alcohol use are one of the major factors that influence morbidity and mortality and should be considered together. In their article Clustering behaviours among 13year-old Portuguese adolescents, Fraga et al. analysed behaviours such as the food intake, smoking and alcohol use of young adolescents, identifying, in conclusion, a clustering of behaviours.

Children and adolescents grow up differently nationwide. They are faced with different historical and social background and incisive events. Sexual and physical abuse can lead to suicide attempts or alcohol abuse at an early stage. In Comparison of childhood adversities and their possible consequences in Poland and Germany, Hardt et al. assessed how people have grown up in these different countries. The underlying data can be used for educational policy-making.

Many risk factors are known in connection to child neglect, substance addiction and abuse or insufficient child care. The question is how to deal with these findings and which prevention strategies, interventions and adequate policies can be implemented. In her article Prevention science and disability studies: a postgraduate doctoral study overview, Bašić gives an insight into a new PhD study aimed at scientists who would be trained to improve their knowledge in prevention science and would then be able to integrate this knowledge into theoretical research and professional practice.

Pacic-Turk and Boskovic conclude that there is no single approach available in addiction prevention. Furthermore, psychologists should be integrated already in primary prevention activities. With their manuscript The role of psychologists and the psychological profession in health promotion and addiction prevention, the authors wanted to assess different orientations for health promotion relating addiction and abuse prevention with special emphasis on the role of psychologists and the psychological profession.

Starting an intervention or a strategy needs a comprehensive analysis of an existing situation. Roviš focused on analysing the situation of substance abuse in Croatia. On this basis, possibilities for Capacity building in health promotion and drug prevention in Croatia are described. Furthermore, the underlying data served as contribution to the development of the postgraduate course on health promotion and drug abuse prevention, financed by the European Commission-TEMPUS CD_JEP-41030-2006 (HR).

\section{References}

European Monitoring Centre for Drugs and Drug Addiction (2008) Annual Report 2008: the state of the drugs problem in Europe. EMCDDA, Lisbon. Available via http://www.emcdda.europa.eu/ publications/annual-report/2008. Cited 07 Mar 2011

World Health Organization (2004) Global Status Report on Alcohol 2004. WHO, Rome. Available via http://www.who.int/substance_abuse/ publications/alcohol/en/index.html. Cited 07 Mar 2011 